\title{
Pleiotropic morphological and antibiotic deficiencies result from mutations in a gene encoding a tRNA-like product in Streptomyces coelicolor A3(2)
}

\author{
Elizabeth J. Lawlor, Howard A. Baylis, and Keith F. Chater \\ Agricultural and Food Research Council Institute of Plant Science Research, John Innes Institute, Norwich, NR4 7UH, UK
}

In Streptomyces coelicolor, bldA mutants are defective in antibiotic production and the development of aerial hyphae and spores. Subcloning analysis showed that sequences spanning an NcoI site in cloned bldA+ DNA were needed to allow complementation of a bldA mutant. Nucleotide sequencing revealed a tRNA-like sequence 9 bp downstream from the $N$ coI site. Five independent bldA mutations all fell in a 16-bp region in the tRNA-like sequence, one of them changing the putative anticodon. In RNA dot-blot analysis, hybridization was detected with a probe specific for the tRNA-like transcript but not with a probe for "anti-tRNA-like" transcripts. The transcripts detected were all in the salt-soluble RNA fraction and accumulated relatively late in growth. It is postulated that bldA specifies a tRNA that would recognize the codon UUA (for leucine). This codon is very rare in Streptomyces genes [which generally contain $>70 \mathrm{~mole} \%(\mathrm{G}+\mathrm{C})$ ], suggesting a possible role for bldA in translational control of development.

[Key Words: Differentiation; translational regulation; secondary metabolism; sporulation]

Received September 3, 1987; revised version accepted September 17, 1987.

The genus Streptomyces comprises Gram-positive soil bacteria that grow as a branching vegetative mycelium, on which aerial, sporogenous hyphae develop, presumptively in response to nutritional limitation. Numerous antibiotics, including many that are valuable to man, are produced by this group of bacteria, often at a time coinciding with the formation of aerial hyphae.

In different Streptomyces species, studies of morphological mutants have variously implicated arginine metabolism (Meade 1985), guanosine nucleotides (Ochi 1986), and extracellular diffusible factors (Khokhlov 1986 ) in both sporulation and antibiotic production (reviewed by Chater 1984). In the genetically well-characterized S. coelicolor, bldA mutants are one of several classes of mutants defective in different stages of development while being apparently unimpaired in vegetative growth (Merrick 1976). On minimal agar medium containing glucose or cellobiose as a carbon source, bldA mutant colonies produce no recognizable aerial hyphae or spores; instead, the surface hyphae undergo frequent septation and fragmentation, which may be an aberrant form of the sporulation process (Chater and Merrick 1979). In addition, production of four quite different antibiotics (two of them pigmented) made by the wild-type strain is abolished. On other carbon sources, such as mannitol or maltose, aerial mycelium development and sporulation appear to occur normally, but antibiotic production is not restored (Merrick 1976). The bldA gene was recently cloned on a Streptomyces temperate phage vector as a 5.6-kb PstI fragment (Piret and Chater 1985). Here, we present the nucleotide sequence of a part of this fragment containing the bldA gene. The location of five bldA mutations in this sequence, coupled with analysis of bldA RNA, leads us to suggest that bldA specifies a tRNA for the rare leucine codon UUA and that use of this codon may allow translational control of development.

\section{Results and discussion}

\section{bldA mutations lie in a potential tRNA gene}

Subcloning analysis showed that a BglII-PstI fragment of approximately $870 \mathrm{bp}$ (fragment A, Fig. 1), derived from the $5.6-\mathrm{kb}$ PstI fragment originally cloned by Piret and Chater (1985), gave bldA complementation results identical to those obtained with the larger fragment (J.M. Piret and E.J. Lawlor, unpubl.). Following the observation that cloning the $5.6-\mathrm{kb}$ Pst I fragment at high copy number did not disrupt differentiation (J.M. Piret, pers. comm.|, further subcloning and complementation tests were carried out using a multicopy plasmid vector. The results suggested that sequences spanning an $\mathrm{NcoI}$ site (Fig. 1) were required for bldA expression because fragments $\mathrm{B}$ and $\mathrm{C}$ failed to complement a bldA mutation (bldA62). Occasional wild-type recombinant colonies were obtained with fragment $\mathrm{C}$, indicating that the 


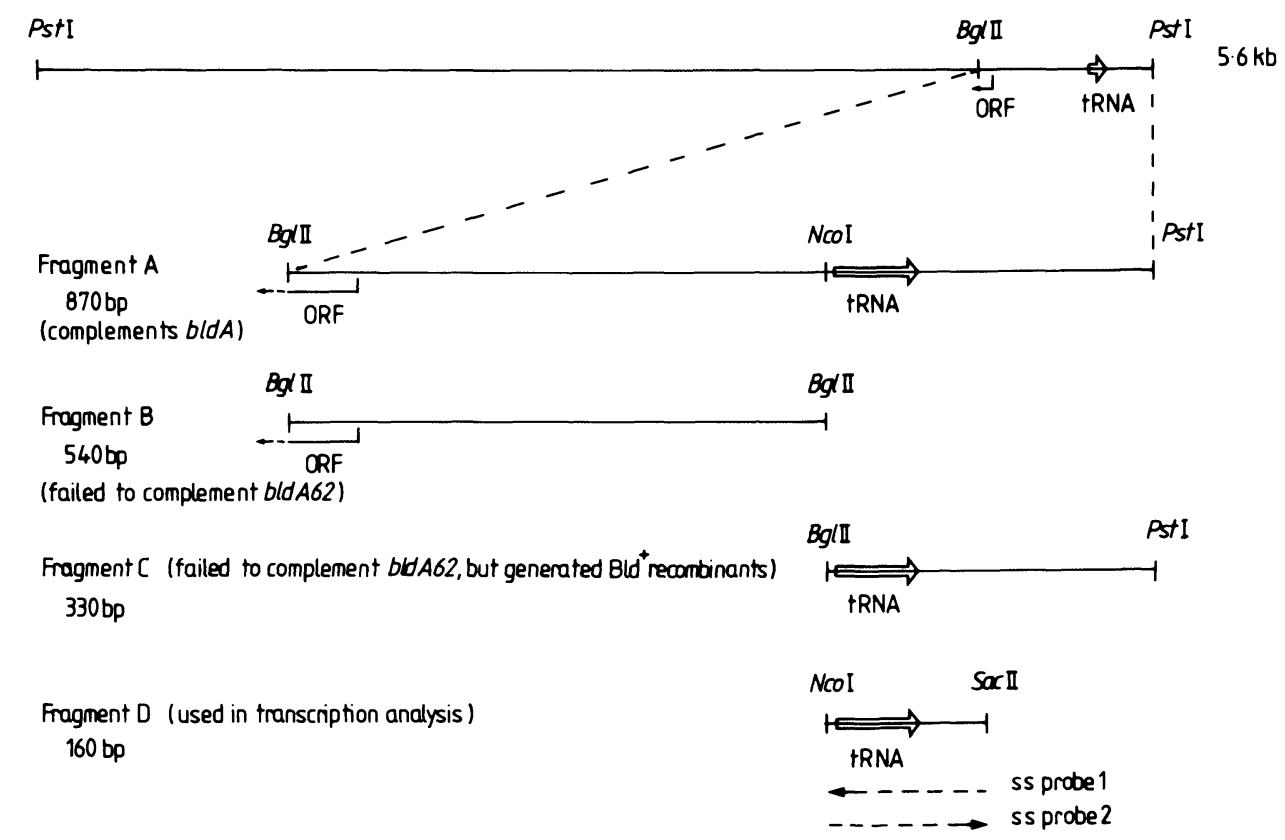

Figure 1. Fragments used for the localization, sequencing, and transcription analysis of bldA. Colonies obtained by transformation of S. coelicolor J395 and S. coelicolor J668 with a plasmid carrying fragment A all showed the Bld ${ }^{+}$phenotype; those obtained with plasmids carrying either fragment $\mathrm{B}$ or $\mathrm{C}$ generally retained the bldA mutant phenotype. Fragment $\mathrm{D}$, inserted in $\mathrm{M} 13 \mathrm{mp} 19$, was used to generate two radioactively labeled single-stranded probes (ss probes 1 and 2; see Materials and methods) for transcription analysis (Fig. 4).

bldA62 mutation lay to the right of the NcoI site. Fragments $\mathrm{B}$ and $\mathrm{C}$ also failed to complement a second bldA mutation (bldA39); no wild-type recombinant colonies were seen among the few transformants obtained with this particularly poorly transformable strain.

The nucleotide sequence of fragment $\mathrm{A}$ was determined (Fig. 2). Using the computer program "Frame" (Bibb et al. 1984), only one (truncated) potential open reading frame (ORF) was identified, beginning at a GTG triplet $69 \mathrm{bp}$ from the left-hand end of fragment $\mathrm{A}$, and reading leftward through the $B g I I I$ site. The finding that bldA62 lay to the right of the NcoI site (see above) made it unlikely that this ORF was bldA. However, further computer analysis of the nucleotide sequence using the program of Staden (1980) revealed a potential tRNA gene reading rightward from a position $9 \mathrm{bp}$ to the right of the NcoI site (Fig. 3). If this tRNA were the bldA gene product, cleavage at the $N c o$ site would prevent complementation of bldA mutants, because it would presumably separate the tRNA gene (and any genes downstream of it) from its promoter and from any transcribed leader sequences that might be important for correct processing of the transcript to give a mature tRNA. This, combined with the apparent absence of other potential genes from the sequenced DNA, suggested that the potential tRNA gene was indeed bldA.

The nucleotide sequences of DNA fragments carrying five independent bldA mutations [including four previously shown to be alleles (Piret and Chater 1985)] were determined. The 870-bp fragment A (Fig. 1) from each mutant differed by only 1 bp from the wild-type se- quence. Each mutation was in the potential tRNA gene (Fig. 3).

The bldA gene specifies a small RNA that accumulates late in growth

Although the double-stranded sequence potentially encoding a tRNA was indeed bldA (or a part of it), it remained possible that bldA was transcribed from right to left through this sequence. Using primed synthesis on single-stranded templates containing each orientation of the 160-base fragment $\mathrm{D}$ (Fig. 1), probe 1, specific for a tRNA-like transcript, and probe 2, specific for an antitRNA-like transcript, were obtained. In Southern blot analysis of total S. coelicolor DNA, using probe 1, only fragments of the sizes predicted from the restriction map of the bldA region were detected (results not shown). The probes were therefore specific for bldA transcripts and were used to analyze RNA that had been isolated at different growth stages from a bldA ${ }^{+}$strain and fractionated by precipitation in $3 \mathrm{~m}$ sodium acetate (in which RNA larger than about $6 \mathrm{~S}$ is preferentially precipitated). Hybridization was detected only with probe 1 and only with the soluble (sRNA) fraction that contains smaller RNA species such as 5S RNA and tRNA (Fig. 4). It was strongest in RNA isolated from 36-hr cultures (just before aerial hyphae appeared). Thus, only the potential tRNA gene (and not its complementary strand) is detectably transcribed, and its product accumulates as a small RNA at a time compatible with its role in differentiation and antibiotic production. 
Downloaded from genesdev.cshlp.org on April 26, 2023 - Published by Cold Spring Harbor Laboratory Press

Putative tRNA needed for development

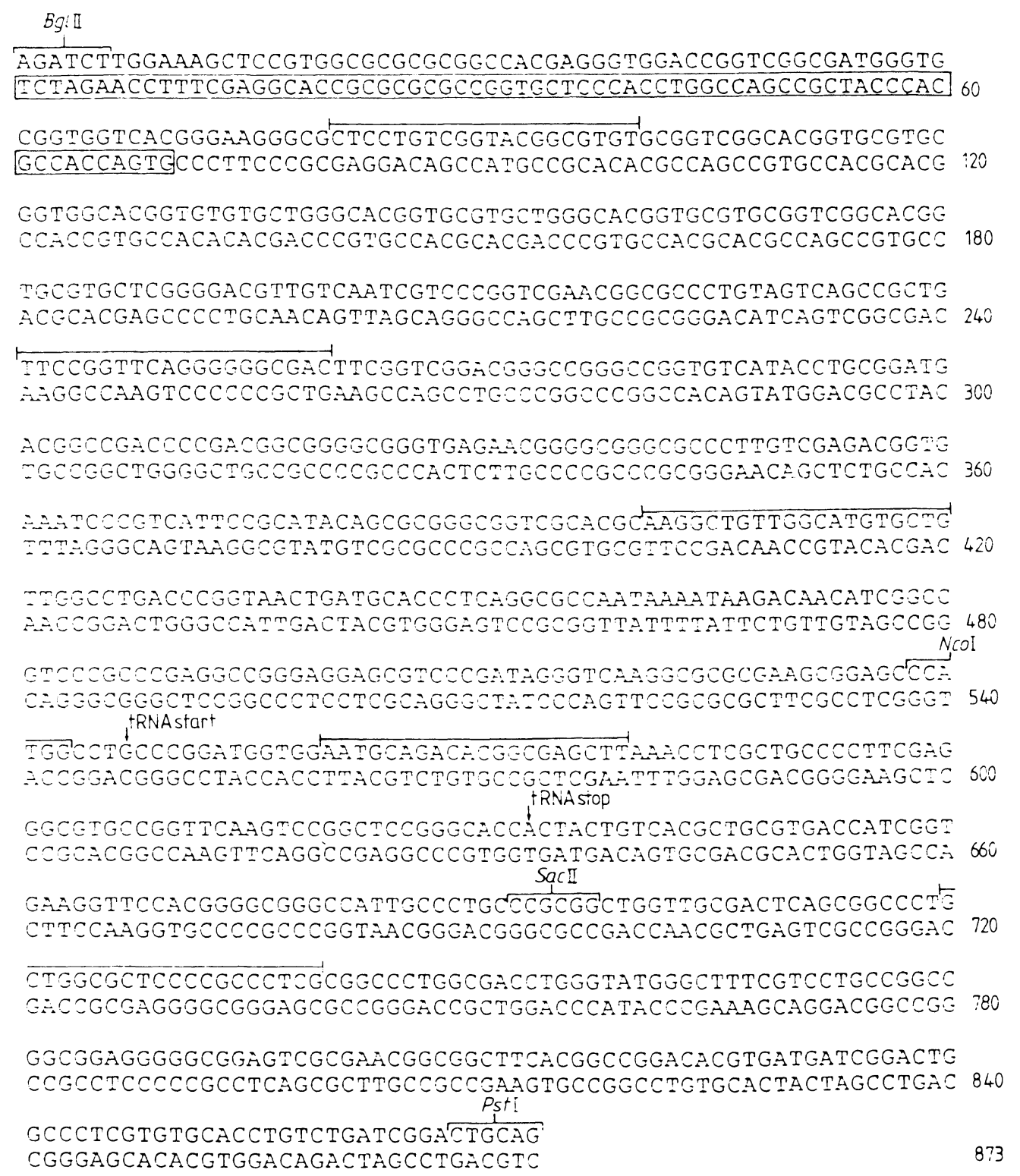

Figure 2. Nucleotide sequence of fragment A. The boxed nucleotides form an incomplete ORF, and the black bars indicate the sequences of the 20-base oligonucleotide primers used to sequence bldA mutant alleles (Fig. 3). The latter experiments confirmed the sequence across the $\mathrm{NcoI}$ site shown here.

How $t R N A$-like would the proposed bldA gene product be?

These results provide strong evidence that bldA specifies a tRNA-like product. How tRNA-like would it be? The stems and loops of its proposed secondary structure are consistent with those of tRNAs, and it has a typical "cloverleaf" form (Gauss et al. 1979). Ignoring modified bases (which cannot be deduced from the DNA sequence), the potential tRNA contains all the invariant and semiinvariant residues present in almost all tRNAs (excluding initiator tRNAs) involved in protein synthesis (Rich and RajBhandary 1976), except the highly conserved GG pair at nucleotides 18 and 19 in the D loop. The absence of one $G$ of this pair is striking, but there are examples of tRNAs where both $G$ residues are absent (Roberts 1972). The anticodon would recognize the codon UUA, and so the bldA-gene product can be designated tRNA ${ }_{\text {TTA }}^{\text {Leu }}$. It showed highest homology $(65 \%)$ to a Bacillus subtilis tRNA TTA $_{\text {LTA }}^{\text {eu }}$ (Wawrousek et al. 1984) and greater homology to leucyl tRNAs with nonhomologous anticodons [for example, Escherichia coli tRNA ${ }_{\text {CTG }}^{\text {Leu }}(57 \%)$ (Sprinzl et al. 1985)] than to nonleucyl tRNAs [for example, B. subtilis tRNA ${ }_{\text {TCC }}^{\text {Ser }}(39 \%)$ (Wawrousek et al. 1984)].

What effects might the sequenced bldA mutations have on tRNA structure and function? The bldA39 mutation changes the anticodon to UGA, which would recognize the UCA (serine) codon. The bldA16, bldA62, and bldA1 mutations result in mismatched base pairs in 


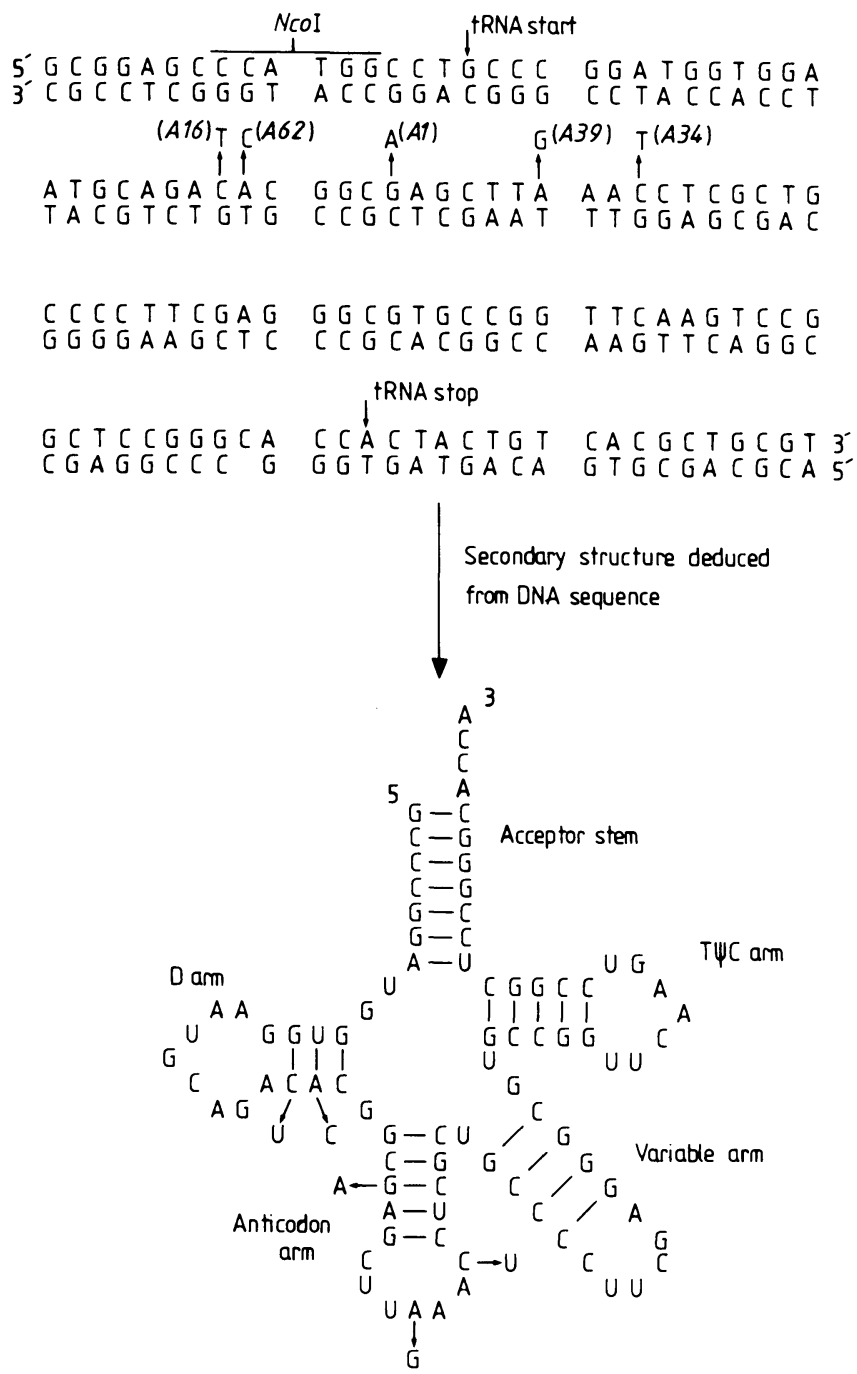

Figure 3. Deduced secondary structure of the potential tRNA and the positions of five bldA point mutations. The base change for each bldA mutation is shown, together (in the upper part of the diagram) with the allele number in parentheses.

either the $\mathrm{D}$ stem or the anticodon stem, reducing the stability of the secondary structure. The bldA34 mutation lies at $\mathrm{N}_{38}$ in the anticodon loop where the (often highly modified) residues play a part in anticodoncodon recognition (Bouadloun et al. 1986; Ericson and Björk 1986). This mutation may therefore prevent an important modification.

\section{How could the bldA-gene product influence differentiation?}

Although a variety of nontranslational roles of tRNAlike molecules have been reported (see the end of this section), we first discuss the most obvious hypothesis for bldA action-that its product might play a crucial role in differentiation simply by influencing translation, for example, by changes in its abundance or degree of modification.

In $B$. subtilis the tRNA profile changes at least slightly during sporulation, and these changes are thought to be due to post-translational modification (Vold 1985; Henner and Steinberg 1979), but it is not known whether they influence the course of sporulation. The high G $+\mathrm{C}$ content of Streptomyces DNA might allow (or even result from) the use of A + T-rich codons as regulatory signals. In a compilation of 17 sequenced Streptomyces genes provided by M.J. Bibb (pers. comm.), there was only one example of a TTA codon, in the hyg gene of $S$. hygroscopicus (Zalacain et al. 1986). In addition, recent sequence analysis has shown that the carB gene of $S$. thermotolerans (Epp et al. 1987) contains two TTA codons and that the sph gene of $S$. glaucescens (Vögtli and Hütter 1987) contains one TTA codon. Overall, this represents a frequency of usage for this codon of less than $1 \%$, CTG and CTC being preferentially used to encode leucine. Thus, it is possible that limited availability of the bldA tRNA TTA $_{\text {TIA }}^{\text {Leu }}$ S. coelicolor restricts the translation of mRNA species containing UUA codons and that efficient translation of at least one such mRNA is necessary for normal development. This hypothesis requires that there should be no other tRNA capable of translating UUA codons efficiently. Although Southern blotting (results not shown) indicated that $S$. coelicolor DNA contains no other sequences at least $70 \%$ homologous to bldA, this does not exclude the possibility of a less homologous tRNA with the same anticodon. Although constrained by the lack of information concerning modified residues, consideration of the "wobble hypothesis" as originally formulated (Crick 1966) indicates that only tRNAs with the anticodon UAA are able to read UUA codons. However, wobble has also been reported at the first position of the codon, with pairing occurring between $\mathrm{G}$ and $\mathrm{U}$ residues (Lin et al. 1986 and references therein). This potentially allows leucyl tRNAs with the anticodon UAG to translate UUA codons.

Alternatively, the bldA tRNA could be involved in a process other than ribosome-mediated protein synthesis. In other organisms, tRNAs have been implicated in nonribosomal amino-terminal addition of amino acids to proteins (Soffer and Horinishi 1969), donation of the lysyl group of lysyl-tRNA in the formation of O-L-lysyl phosphatidylglycerol in Staphylococcus aureus (Lennarz

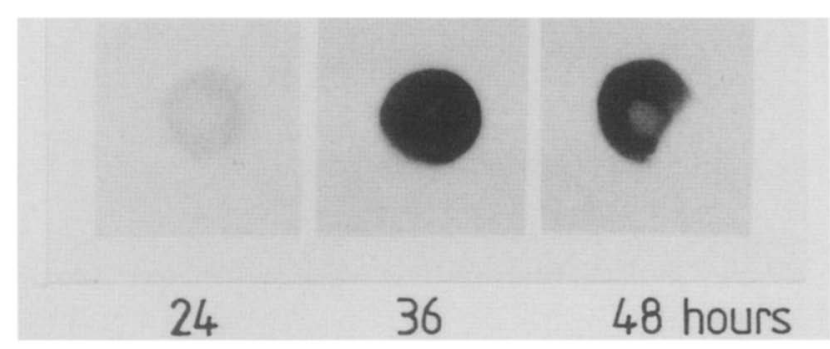

Figure 4. Hybridization between $3 \mu \mathrm{g}$ of the salt-soluble RNA fractions and probe 1 (Fig. 1), indicating that a bldA tRNA-like transcript accumulates relatively late in growth. No signals were detected between probe 1 and the salt-insoluble RNA fractions or between probe 2 (Fig. 1) and either the salt-soluble or salt-insoluble RNA fractions. 
et al. 1971), and peptidoglycan synthesis in staphylococci (Steward et al. 1971). Moreover, there are requirements for an arginine tRNA for DNA replication (Mullin et al. 1984; Garcia et al. 1986) and a serine tRNA for cell division (Tamura et al. 1984) in E. coli. It is not clear whether these latter effects are exerted through the translation machinery or via some other activity of these particular tRNA species.

Elucidation of both the precise mode of action of tRNA ${ }_{\text {TTA }}^{\text {Leu }}$ and the mechanism of temporal control of bldA expression will provide a basis for a number of interesting future experiments. These matters will also be of some relevance to the commercial production of antibiotics by Streptomyces fermentations.

\section{Materials and methods}

\section{Subcloning of bldA}

Fragments A, B, and C (Fig. 1) were ligated with the multicopy plasmid vectors pIJ486 and PIJ487 (Ward et al. 1986), cleaved at appropriate sites in their oppositely oriented polylinker sequences, and introduced into Streptomyces lividans TK24 by transformation (Hopwood et al. 1985). For the easier subcloning of fragments B and $\mathrm{C}$, the NcoI site was converted to a BgllI site by end filling with the Klenow fragment of DNA polymerase I and attachment of a synthetic BglII linker (Maniatis et al. 1982). Plasmids of the correct structure were identified by restriction enzyme analysis and introduced into $S$. coelicolor J395 (bldA62) (Piret and Chater 1985) and S. coelicolor J668 (bldA39) (Merrick 1976) by transformation. (Note that bldA mutants were generally transformed at relatively low frequencies.)

\section{Cloning of bldA mutant alleles}

The bldA mutations analyzed were cloned from the following strains: J668 (bldA39) and J673 (bldA16) (Merrick 1976); and J406 (bldA1), J394 (bldA34), and J395 (bldA62) (D.A. Hopwood and K.F. Chater, unpubl.). The mutations were cloned in vivo by recombination between $\phi \mathrm{C} 31 \mathrm{KC} 603$, carrying the cloned bldA gene as a 5.6-kb PstI fragment, and the bldA region of the respective bldA mutant chromosome as described by Piret and Chater (1985). The 870-bp BglII-PstI fragment A (Fig. 1) from each mutant was ligated with PstI- and BamHI-cleaved M13mp19 (Norrander et al. 1983) and introduced into E. coli JM101 (Messing 1979) by transformation (Bankier and Barrell 1983).

\section{DNA sequence analysis}

The DNA sequences of both strands of fragment A carrying the wild-type bldA allele were determined by the chemical degradation method (Maxam and Gilbert 1980), using fragments uniquely labeled at the BgIII, $N c o I$ (in some cases after its conversion to a $B g$ III site), and a vector HindIII site adjacent to the PstI site of the cloned fragment. The DNA sequence of one strand of fragment A was determined for each bldA mutant allele by the chain-terminating procedure (Bankier and Barrell 1983) using the synthetic oligonucleotide primers shown in Figure 2 .

\section{Preparation of probes}

The $5^{\prime}$ single-stranded ends generated by NcoI and the 3' single-stranded ends generated by SacII of the 160-bp fragment
D (Fig. 1) were respectively filled in or digested with the Klenow fragment of DNA polymerase I (Maniatis et al. 1982) and ligated with $S m a \mathrm{I}$-cleaved $\mathrm{M} 13 \mathrm{mpl} 19$ and introduced into $E$. coli JM101 by transformation. Derivatives of M13mpl9 containing each orientation of fragment $\mathrm{D}$ were detected by sequence analysis (Bankier and Barrell 1983) and were used to prepare ${ }^{32} \mathrm{P}$-labeled single-stranded DNA probes by primed synthesis (Biggin et al. 1984). Labeled DNA was separated from unincorporated nucleotides by passage through a Sephadex G-100 column (Hopwood et al. 1985) and denatured at $90^{\circ} \mathrm{C}$ for $10 \mathrm{~min}$ prior to use. Probe 1 was prepared from template containing fragment D oriented such that the SacII end of the fragment was next to the primer site for in vitro DNA synthesis, and probe 2 from template containing fragment $D$ in the opposite orientation.

\section{Southern blots}

Southern blots were performed as described in Hopwood et al. (1985). The filters were washed in $3 \times$ SSC/0.1\% SDS or $0.2 \times$ $\mathrm{SSC} / 0.1 \%$ SDS at $70^{\circ} \mathrm{C}$, according to the degree of homology being sought $170 \%$ and $90 \%$, respectively, in the two sets of conditions|.

\section{Dot blots}

RNA was isolated from cultures of $S$. coelicolor $\mathrm{J} 1507\left(\mathrm{bldA} \mathrm{A}^{+}\right)$ (Chater and Bruton 1983), grown for different lengths of time on the surface of cellophane sheets laid on R2YE medium (Hopwood et al. 1985). The RNA was size-fractionated by two precipitations in $3 \mathrm{M}$ sodium acetate in which RNA larger than $6 \mathrm{~S}$ precipitates (Kirby et al. 1967). The fractionation was checked by agarose gel electrophoresis. RNAs $(1.5,3$, and $6 \mu \mathrm{g})$ were "dotted" onto nitrocellulose filters and hybridized with probes 1 and 2, as described in Hopwood et al. (1985).

\section{Acknowledgments}

We thank Gary Janssen for valuable help with sequencing procedures, Jacqueline Piret for providing bldA-containing phages and unpublished data, Mervyn Bibb for the use of his compilation of Streptomyces gene sequences, and David Hopwood for helpful comments on the manuscript. E.J.L. and H.A.B. were the recipients of John Innes Foundation Research Studentships.

\section{References}

Bankier, A.T. and B.G. Barrell. 1983. Shotgun DNA sequencing. In Techniques in the life sciences: Nucleic acid biochemistry (ed. R.A. Flavell), pp. 1-34. Elsevier Press, Ireland.

Bibb, M.J., P.R. Findlay, and M.W. Johnson. 1984. The relationship between base composition and codon usage in bacterial genes and its use for the simple and reliable identification of protein coding sequences. Gene 30: 157-166.

Biggin, M., P.J. Farrell, and B.G. Barrell. 1984. Transcription and DNA sequence of the BamHI L fragment of B95-8 EpsteinBarr virus. EMBO J. 3: 1083-1090.

Bouadloun, F., T. Srichaiyo, L.A. Isaksson, and G.R. Björk. 1986. Influence of modification next to the anticodon in tRNA on codon context sensitivity of translational suppression and accuracy. J. Bacteriol. 166: 1022-1027.

Chater, K.F. 1984. Morphological and physiological differentiation in Streptomyces. In Microbial development (ed. R. Losick and L. Shapiro), pp. 89-115. Cold Spring Harbor Laboratory, Cold Spring Harbor, New York.

Chater, K.F. and M.J. Merrick. 1979. Streptomyces. In Develop- 
mental biology of prokaryotes (ed. J.H. Parish), pp. 93-114. Blackwell Scientific Publications, Oxford.

Chater, K.F. and C.J. Bruton. 1983. Mutational cloning in Streptomyces and the isolation of antibiotic production genes. Gene 26: 67-78.

Crick, F.H.C. 1966. Codon-anticodon pairing: the wobble hypothesis. J. Mol. Biol. 19: 548-555.

Epp, J.K., S.G. Burgett, and B.E. Schoner. 1987. Cloning and nucleotide sequence of a carbomycin resistance gene from Streptomyces thermotolerans. Gene 53: 73-83.

Ericson, J.U. and G.R. Björk. 1986. Pleiotropic effects induced by modification deficiency next to the anticodon of tRNA from Salmonella typhimurium LT2. I. Bacteriol. 166: $1013-1021$.

Garcia, G.M., P.K. Mar, and J.R. Walker. 1986. The Escherichia coli dnaY gene encodes an arginine transfer RNA. Abstracts of the annual meeting of the American Society for Microbiology. Washington, D.C. Abstract H-160.

Gauss, D.H., F. Gruter, and M. Sprinzl. 1979. Compilation of tRNA sequences. Nucleic Acids Res. 6: r1-r19.

Henner, D.J. and W. Steinberg. 1979. Transfer ribonucleic acid synthesis during sporulation and spore outgrowth in $\mathrm{Ba}$ cillus subtilis studied by two-dimensional polyacrylamide gel electrophoresis. J. Bacteriol. 140: 555-566.

Hopwood, D.A., M.J. Bibb, K.F. Chater, T. Kieser, C.J. Bruton, H.M. Keiser, D.J. Lydiate, C.P. Smith, J.M. Ward, and H. Schrempf. 1985. Genetic manipulation of Streptomyces: A laboratory manual. The John Innes Foundation, Norwich, England.

Khokhlov, A.S. 1986. Actinomycete autoregulators. In Biological, biochemical, and biomedical aspects of actinomycetes. Proceedings of 6th Int. Symp. on Actinomycetes Biology (ed. G. Szabó, S. Biró, and M. Goodfellow), pp. 791-798. Akademiai Kiado, Budapest.

Kirby, K.S., E. Fox-Carter, and H. Guest. 1967. Isolation of deoxyribonucleic acid and ribosomal ribonucleic acid from bacteria. Biochem. J. 104: 258-262.

Lennarz, W.J., J.A. Nesbitt III, and J. Reiss. 1966. The participation of sRNA in the enzymatic synthesis of $O$-L-lysyl phosphatidylglycerol in Staphylococcus aureus. Proc. Natl. Acad. Sci. 55: 934-941.

Lin, J.P., M. Aker, K.C. Sitney, and R.K. Mortimer. 1986. First position wobble in codon-anticodon pairing: amber suppression by a yeast glutamine tRNA. Gene 49: 383-388.

Maniatis, R., E.F. Fritsch, and J. Sambrook. 1982. Molecular cloning: A laboratory manual. Cold Spring Harbor Laboratory, Cold Spring Harbor, New York.

Maxam, A.M. and W. Gilbert. 1980. Sequencing end-labeled DNA with base specific chemical cleavages. Methods Enzymol. 65: 499-560.

Meade, H. 1985. Cloning of $\arg G$ from Streptomyces: loss of gene in $\mathrm{Arg}^{-}$mutants of $S$. cattleya. Bio/Technology 3: $917-918$.

Merrick, M.J. 1976. A morphological and genetic mapping study of bald colony mutants of Streptomyces coelicolor. I. Gen. Microbiol. 96: 299-315.

Messing, J. 1979. A multipurpose cloning system based on the single stranded DNA bacteriophage M13. Recombinant DNA Technical Bulletin, NIH Publication 99: 43-48.

Mullin, D.A., G.M. Garcia, and J.R. Walker. 1984. An E. coli DNA fragment 118 base pairs in length provides $d n a Y$ complementing activity. Cell 37: 669-674.

Norrander, J., T. Kempe, and J. Messing. 1983. Construction of improved M13 vectors using oligodeoxynucleotide-directed mutagenesis. Gene 26: 101-106.

Ochi, K. 1986. A decrease in GTP content is associated with aerial mycelial formation in Streptomyces MA406-A-1. I. Gen. Microbiol. 132: 299-305.

Piret, J.M. and K.F. Chater. 1985. Phage-mediated cloning of bldA, a region involved in Streptomyces coelicolor morphological development and its analysis by genetic complementation. J. Bacteriol. 163: 965-972.

Rich, A. and U.L. RajBhandary. 1976. Transfer RNA molecular structure, sequence, and properties. Annu. Rev. Biochem. 45: $805-860$.

Roberts, R.J. 1972. Structures of two glycyl-tRNAs from Staphylococcus epidermidis. Nat. New Biol. 237: 44-45.

Soffer, R.L. and H. Horinishi. 1969. Enzymatic modification of proteins. I. General characteristics of the arginine transfer reaction in rabbit liver cytoplasm. J. Mol. Biol. 43: 163-175.

Sprinzl, M., T. Vorderwülbecke, and T. Hartmann. 1985. Compilation of sequences of tRNA genes. Nucleic Acids Res. 13: $r 51-r 104$.

Staden, R. 1980. A computer program to search for tRNA genes. Nucleic Acids Res. 8: 817-825.

Steward, T.W., R.J. Roberts, and J.L. Strominger. 1971. Novel species of tRNA. Nature 230: 36-38.

Tamura, F., S. Nishimura, and M. Ohki. 1984. The E. coli divE mutation, which differentially inhibits synthesis of certain proteins, is in tRNA 1 Ser. EMBO J. 3: 1103-1107.

Vögtli, M. and R. Hütter. 1987. Characterisation of the hydroxystreptomycin phosphotransferase gene $(s p h)$ of Streptomyces glaucescens: nucleotide sequence and promoter analysis. Mol. Gen. Genet. 208: 195-203.

Vold, B.S. 1985. Structure and organisation of genes for transfer ribonucleic acid in Bacillus subtilis. Microbiol. Rev. 49: $71-80$.

Ward, J.M., G.R. Janssen, T. Kieser, M.J. Bibb, and M.J. Buttner. 1986. Construction and characterisation of a series of multicopy promoter-probe plasmid vectors for Streptomyces using the aminoglycoside phosphotransferase gene from Tn5 as indicator. Mol. Gen. Genet. 203: 468-478.

Wawrousek, E.F., N. Narashima, and J.N. Hansen. 1984. Two large clusters with thirty-seven transfer RNA genes adjacent to ribosomal RNA gene sets in Bacillus subtilis. J. Biol. Chem. 259: 3694-3702.

Zalacain, M., A. Gonzales, M.C. Guerro, R.J. Mattaliano, F. Malpartida, and A. Jimenez. 1986. Nucleotide sequence of the hygromycin B phosphotransferase gene from Streptomyces hygroscopicus. Nucleic Acids Res. 14: 1565-1581. 


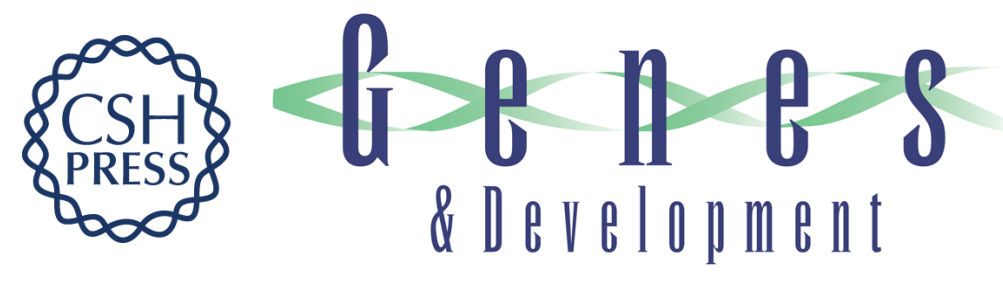

\title{
Pleiotropic morphological and antibiotic deficiencies result from mutations in a gene encoding a tRNA-like product in Streptomyces coelicolor A3(2).
}

\author{
E J Lawlor, H A Baylis and K F Chater
}

Genes Dev. 1987, 1:

Access the most recent version at doi:10.1101/gad.1.10.1305

References This article cites 31 articles, 8 of which can be accessed free at:

http://genesdev.cshlp.org/content/1/10/1305.full.html\#ref-list-1

License

Email Alerting Receive free email alerts when new articles cite this article - sign up in the box at the top

Service right corner of the article or click here.

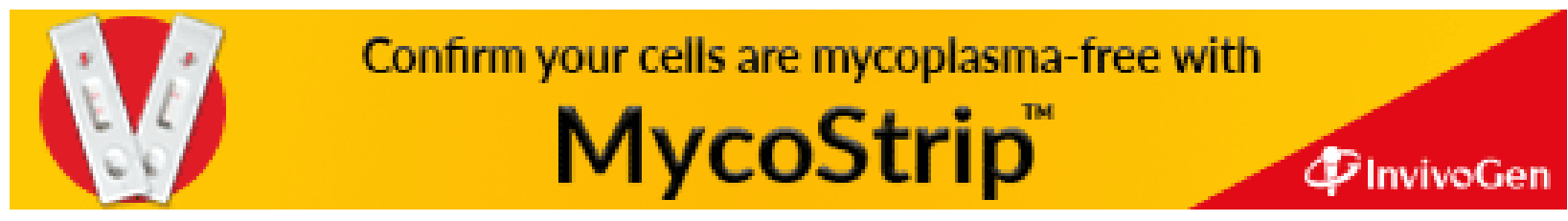

